\title{
A Systemic Investigation to Compare the Relationship of Sleep Disturbances and its Outcomes in Normal and DS Children
}

\author{
Priya Chandrasekhar ${ }^{1 *}$, Varshini Chandrasekhar ${ }^{1}$ and Surekha \\ Ramachandran $^{2}$ \\ ${ }^{1}$ Department of Paediatrics, Indira Health Care, Chennai, India \\ ${ }^{2}$ Department of Rehabilitation, Down Syndrome Federation of India, Chennai, India \\ *Corresponding Author: Priya Chandrasekhar, Department of Pediatrics, Indira \\ Child Care, Chennai, Tamil Nadu, India.
}

Received: May 31, 2021

Published: September 24, 2021

(C) All rights are reserved by Priya

Chandrasekhar., et al.

\begin{abstract}
Background: Down syndrome (trisomy 21) is a genetic disorder caused by the presence of all or a portion of a third chromosome 21. OSA is one of the most common co- morbidities in people who have DS. There are lot of research happening to understand the correlation between the DS and OSA in children.

Objective: The main objective of this pilot study was to determine the sleep characteristics and daily life habits in a group of children with Down syndrome, as well as to find out the relation between sleep disturbances and daily life habit achievement when compared to normal children in relation to sleep pattern with age differences.

Methods: Totally 49 DS children were identified at different ages. We selected 3- 5 yrs 15 children, 5 - 8 yrs 8 children, 8 - 10 yrs 11 children, more than 10yrs we selected 15 children randomly. Normal children served as control and the normal children data was used only for comparison only.

Results: The bedtime resistance of the children with DS had symptoms of falling asleep in own bed. The sleep behaviour of the children with DS had earlier wake times and bedtimes, leading to significantly (**p $<0.01$ ) more hours of sleep during nights, largely due to significantly earlier bedtimes. There was mild statistically significant $(* p<0.05)$ difference in the amount of sleep time compared to normal children. In night waking of the children with DS had difference when compared to normal children, leading to troubling in getting sleep during nights after the child wake up. The morning waking of the children with DS was identified that the child wakes up by own. It is also noted that the child is tired during day and some sleep during day time which is also significant $\left({ }^{*} p<0.05\right)$.

Conclusion: The behaviour and growth of the children improve after successful treatment of obstructive sleep apnea syndrome. The understanding of the sleep fragmentation in children with DS may lead to more appropriate treatment, resulting in an improvement of their psychomotor development.
\end{abstract}

Keywords: Down Syndrome; Obstructive Sleep Apnea; Sleep Behaviour

\section{Introduction}

Obstructive sleep apnoea (OSA) is a sleep-related breathing condition that is becoming more common. In OSA, the pharyngeal airway narrows and becomes obstructed during sleep [1]. Long- term health effects of untreated OSA include cardiovascular disease, metabolic disorders, cognitive dysfunction, and depression. Excessive daytime sleepiness, exhaustion, non-refreshing sleep, nocturia, morning headache, irritability, and memory loss are all

Citation: Priya Chandrasekhar., et al. "A Systemic Investigation to Compare the Relationship of Sleep Disturbances and its Outcomes in Normal and DS Children". Acta Scientific Paediatrics 4.10 (2021): 63-70. 
the common symptoms [2]. Untreated OSA has also been linked to lost productivity, as well as workplace and automobile accidents that result in injury and death. Untreated OSA and sleep deprivation result in increased hospital costs. The recommended treatment can help to alleviate symptoms and side effects. Many people with OSA, however, struggle with the first-line therapy, continuous positive airway pressure (CPAP), which has unacceptably low adherence rates. In many cases, non-CPAP therapies (such as oral appliances and upper airway surgery) are beneficial, but their efficacy is variable and unpredictable. As a result, new approaches to treating OSA are needed [3].

The majority of people who have OSA go undiagnosed and untreated which may be due to a lack of awareness of the disorder in some cases. Moreover, stigma related to snoring, lack of access to polysomnography (PSG) and diagnostic services (especially in remote communities and in developing countries), lack of interest with the treatment options and fear of having one's driver's license revoked are some of the barriers that prevent patients from seeking medical help. Furthermore, primary care physicians may not be motivated to investigate an early OSA diagnosis when the patients don't present with symptoms of sleepiness or obesity $[4,5]$. The absence of subjective sleepiness and obesity does not rule out substantial sleep-disordered breathing [6]. Nonetheless, given the severity of the disease, the limitations of current diagnostic and treatment methods, and the serious health, safety, and economic implications of untreated OSA, there is an urgent need to continue raising awareness and developing new strategies to manage and treat this widespread chronic health condition [7].

OSA has a number of contributors and each represents a potential therapeutic target. The recent research findings provide hope for new treatment options for OSA [8]. For example, techniques have been developed to derive information from current clinical PSG trials in order to better guide treatment decisions for OSA based on a cause-driven targeted therapy model. Simple wakefulness upper airway and respiratory physiology tests can also be useful in achieving this goal [9] and this study focuses on these concepts.

\section{Existing clinical measures of OSA}

A systematic in-laboratory PSG is the gold standard procedure for diagnosing sleep-disordered breathing [10]. The apnea-hypop- nea index is the primary criterion for determining the severity of OSA (AHI). This index measures the amount of breathing pauses (apneas) and intervals of diminished airflow (hypopneas) that last longer than 10 seconds and trigger a brief awakening (arousal) or decreased oxygenation per hour of sleep. Although severity cutoffs vary, mild sleep apnea is usually described as 5 - 15 respiratory events per hour of sleep, moderate 15 - 30, and extreme more than 30 respiratory events per hour of sleep [11].

Although in-laboratory PSG is thorough, it is time-consuming, labor-intensive, and expensive (Edwards., et al). Home-monitoring systems aid in the diagnosis process. These vary from limited channel devices that concentrate on a few core signals to a replication of the same measurements used in the laboratory (e.g. oxygen and an airflow sensor). They are most effective for detecting severe illness, assuming patients do not have a lot of comorbidities [12].

Despite the large number of neurophysiological signals gathered during an overnight PSG, the majority of the data is overlooked and treatment decisions are heavily based on the AHI. Although the AHI is still a commonly used clinical and research indicator of OSA severity, it does have some drawbacks. For example, a patient who has had a series of long respiratory events can have significant hypoxemia but a low AHI [13]. Another patient, may have more regular incidents and, as a result, a much higher AHI, but only minor hypoxemia exposure [14]. As a result, the symptoms of OSA hypoxia and its negative influence on the cardiovascular system may be more pronounced in patients with a low AHI. Furthermore, heart rate fluctuations and increased expiratory pharyngeal resistance are linked to non-apneic respiratory events that do not meet the scoring requirements for hypopnea [15]. Breathing disturbances that do not result in significant hypoxemia are often linked to objective daytime sleepiness. Furthermore, the overall AHI has a low correlation with the disease's primary causes and consequences. Recent research suggests that REM sleep apnea may play a larger role in mediating insulin resistance and the cardiovascular consequences of OSA. These examples illustrate the heterogeneity of OSA's clinical manifestations and effects, as well as some of the shortcomings of currently available diagnostic methods [16].

\section{OSA pathophysiology}

OSA pathogenesis is multifactorial, much like clinical heterogeneity. There are two types of causes: anatomical and non-anatomi- 
cal. The possible role of factors other than pharyngeal anatomy and craniofacial structure in OSA pathophysiology has been recognized in recent years. OSA can be caused by a variety of factors, the combination of which is likely to differ significantly between patients [17].

Impaired pharyngeal dilator muscle activity, premature waking to moderate airway narrowing (low respiratory arousal threshold), and unstable regulation of breathing are non-anatomical contributors (high loop gain). Impairment in one or more of these non-anatomical contributors will perpetuate OSA severity when combined with a pharyngeal airway that is susceptible to closure during sleep, as discussed in later parts. Given that OSA only occurs while sleeping, a combination of anatomical predisposition and state-dependent changes in non-anatomical contributors is critical in causing this common disorder [18].

\section{OSA is largely a sleep-dependent anatomical problem}

OSA is a multifactorial condition although some degree of anatomical disability of the upper airway is required. As a result, it's only natural that the majority of OSA treatments focus on resolving the anatomical problem. In people with OSA, imaging studies have shown main pharyngeal anatomical abnormalities. A narrow pharyngeal airway, increased airway length, and some pharyngeal lumen forms, for example, have all been linked to the risk of pharyngeal collapse while sleeping. One or more places in the upper airway may collapse [19].

The dilator muscles, such as the genioglossus, soft palate, lateral pharyngeal walls, and the epiglottis, are pharyngeal structures that can lead to airway crowding and collapse. Obesity increases the risk of occurrence of OSA. In the clinic, neck circumference is regularly assessed and has been used to predict OSA risk. Some of the factors linked to OSA risk and severity include cranial-facial morphology, hyoid bone position, airway surface tension, tongue scalloping, and tongue fat. The high cost of treatment and awake static imaging limits the use of PSG for OSA treatment [20].

\section{OSA and Down syndrome}

Down syndrome (DS) is the most common chromosomal condition, affecting one out of every 700 live births. It is caused by an extra copy of chromosome 21. Patients have multiple dysmorphic characteristics clinically and are at a higher risk of having a variety of disorders such as intellectual disability, congenital heart disorder, hearing and speech difficulties, hypothyroidism, obesity, celiac disease, and so on. OSA is one of the most common comorbidities in people who have DS. We address emerging views on the diagnosis and treatment of OSA in this patient population in this study [21].

Patients that have DS are more likely to develop OSA. According to current figures, the childhood prevalence ranges from 50 to $100 \%$ with adulthood prevalence approaching $100 \%$. study by Maris., et al. $(n>120)$ among patients with DS, states that $66 \%$ had OSA on a complete night polysomnogram (PSG), and about half of these children had serious disease. Furthermore, the researchers discovered that even among children who had no history of snoring or experienced apneas, the majority (53\%) had OSA on PSG and that typical risk factors for OSA, such as tonsil size or BMI z-score, were not linked to the risk of OSA [22].

The high prevalence of OSA in people with DS is likely due to a number of risk factors that contribute to airway obstruction. Other related disorders such as obesity, hypothyroidism, hypotonia, and gastroesophageal reflux are often seen at significantly higher rates than the typical anatomic anomalies (macroglossia, adenotonsillar hypertrophy, midface hypoplasia). As a result, a variety of processes affecting sleep breathing needs to be discussed [23].

The average lifespan of DS patients has increased dramatically in recent decades, and patients are now living well into their 60s. This increased longevity has resulted in a greater emphasis on quality of life, especially as these individuals reach adulthood. Early detection, proactive treatment, and, eventually, optimization of long-term results require a greater understanding of the prevalence of OSA in patients with DS [24].

As previously stated, obstructive sleep apnoea is the most common form of sleep apnoea and is defined by partial obstruction of the upper airways, which are narrower in children with Down syndrome due to enlarged tonsils and/or adenoids, for example. The cause of the obstruction is generally treated with surgery, which is usually very effective. Central sleep apnoea is a much more uncommon condition exacerbated by neurological breathing control problems. The cause of the problem in these situations is much more difficult to treat; however, if the child wears an oxygen mask at night, the symptoms can be alleviated [25].

There have been no comprehensive research on the relationship between sleep and the achievement of normal day-to-day life patterns in children with DS. The aim of this study was to quantify and explain sleep characteristics and daily life habits in a group of children with Down syndrome, as well as to investigate the connection between sleep disturbances and daily life habit achievement. 
Although children with DS have lower levels of everyday life task and habit accomplishment than their peers with TD, it is hypothesized that those with sleep disturbances have even lower levels of daily habit and activity accomplishment.

\section{Methods}

Parents were asked to fill out questionnaires about their child's height and weight (DS and Normal Child), the number of siblings, the extent of cigarette smoke exposure, and whether the child had ever had a sleep examination, sleep apnea diagnosis, tonsillectomy, adenoidectomy, use of a continuous positive airway pressure (CPAP) unit, heart surgery, or a diagnosis of gastrointestinal disease. Body mass index (BMI) percentiles were calculated for reference purposes using height and weight. The mCSHQ (Modified Children's Sleep Habits Questionnaire) was created specifically for these children [26]. Many studies of children's sleep, including studies of children with DS, have used the Children's Sleep Habits Questionnaire (CSHQ). The mCSHQ is a 25-item survey that covers a variety of conceptual domains. Bedtime resistance, sleep behavior, sleep length, sleep anxiety, night waking, and morning waking are the domains. The questions inquire about the duration of a specific sleep habit over the course of a typical week.

Each subscale object, such as "requires parent in the room to sleep," is rated from 1 to 3 , with "usually, 5 - 7 times a week," "sometimes, 2 - 4 times a week," and "rarely, 0 - 1 time a week" being the most common. Depending on the wording of the question, item scores are reversed if appropriate, so that a higher score indicates more sleep disturbance. Subscales for a one-item domain (sleep onset delay) will vary from 1 - 3 to 8 - 24 for an eight-item domain (daytime sleepiness).

\section{Subject selection and withdrawal}

Inclusion criteria

Subject eligibility will be reviewed and documented by the investigator before subjects are included in the study.

Subjects will be eligible for inclusion into the study if they meet the following inclusion criteria:

- $\quad$ Children with DS, confirmed by Karyotyping or genetic analysis.
- Normal child for comparison without any underlying disease.

- The patient and parents is willing and able to comply with scheduled visits and other study procedures.

Exclusion criteria:

Subjects will not be eligible for inclusion into the study if they are identified under any one of the following inclusion criteria:

- $\quad$ Children with DS and cardiac complications.

- The patient has any known laboratory abnormality which, in the opinion of the Investigator, would contraindicate study participation.

\section{Subject recruitment and screening}

Children associated with Down's syndrome Association of Tamilnadu and from Indira Child care center, Chennai.

\section{Early withdrawal of subjects}

- $\quad$ Failure of subject to adhere to protocol requirements.

- $\quad$ Subject consent withdrawal.

\section{Ethics committee}

This study was approved by the Institutional Review Board of Vikram Hosptial, Tamilnadu. A cross- All participants were not consented as this study is subjective. Responses were taken from the child parents. The questionnaire was completed by trained physiotherapist who has good experience in completing the questionnaire upon discussion with the parents.

\section{Statistical evaluation}

Data was collected and analysed statistically using paired ' $\mathrm{t}$ ' test. $\mathrm{P}<0.05$ is considered to be significant. The normal data is self control and it is compared with DS children.

\section{Results}

\section{Bedtime resistance}

On average, bedtime resistance of the children with DS had symptoms of falling asleep in own bed. No other significant findings noted. 


\begin{tabular}{|c|c|c|c|c|}
\hline & $\begin{array}{c}\text { 3 - 5 yrs } \\
\text { (n= 15) }\end{array}$ & $\begin{array}{c}\mathbf{5} \text { - 8 yrs } \\
\text { (n= 8) }\end{array}$ & $\begin{array}{c}\mathbf{8} \text { - 10 yrs } \\
\text { (n= 11) }\end{array}$ & $\begin{array}{c}>10 \text { yrs } \\
\text { (n= 15) }\end{array}$ \\
\hline $\begin{array}{c}\text { Child goes to bed } \\
\text { at the same time at } \\
\text { night. }\end{array}$ & $5 \pm 0.05$ & $3 \pm 0.04$ & $6 \pm 0.01$ & $3 \pm 0.08$ \\
\hline $\begin{array}{c}\text { Child falls asleep } \\
\text { alone in own bed }\end{array}$ & $12 \pm 0.08$ & $4 \pm 0.09$ & $\begin{array}{c}10 \pm \\
0.05^{*}\end{array}$ & $12 \pm 0.07^{*}$ \\
\hline $\begin{array}{c}\text { Child falls asleep in } \\
\text { parent's or sibling's } \\
\text { bed }\end{array}$ & $13 \pm 0.03^{*}$ & $6 \pm 0.08$ & $9 \pm 0.07$ & $11 \pm 0.07$ \\
\hline $\begin{array}{c}\text { Child is afraid of } \\
\text { sleeping in the dark }\end{array}$ & $8 \pm 0.06$ & $6 \pm 0.07$ & $7 \pm 0.08$ & $6 \pm 0.01$ \\
\hline
\end{tabular}

Table 1: ${ }^{*} \mathrm{p}<0.05$

Sleep behaviour

\begin{tabular}{|c|c|c|c|c|}
\hline & $\begin{array}{c}\mathbf{3} \text { - 5 yrs } \\
\text { (n= 15) }\end{array}$ & $\begin{array}{c}\mathbf{5} \text { - 8 yrs } \\
\text { (n= 8) }\end{array}$ & $\begin{array}{c}\mathbf{8} \text { - 10 yrs } \\
\text { (n= 11) }\end{array}$ & $\begin{array}{c}\text { > 10 yrs } \\
\text { (n= 15) }\end{array}$ \\
\hline $\begin{array}{c}\text { Child sleeps } \\
\text { about the same } \\
\text { amount each day. }\end{array}$ & $10 \pm 0.05$ & $5 \pm 0.01$ & $10 \pm 0.09$ & $14 \pm 0.07$ \\
\hline $\begin{array}{c}\text { Child is restless } \\
\text { and moves a lot } \\
\text { during sleep }\end{array}$ & $5 \pm 0.04$ & $3 \pm 0.03$ & $11 \pm 0.02^{*}$ & $\begin{array}{c}13 \pm \\
0.06^{*}\end{array}$ \\
\hline $\begin{array}{c}\text { Child awakens } \\
\text { during the night } \\
\text { and is sweating, } \\
\text { screaming, and } \\
\text { inconsolable }\end{array}$ & $4 \pm 0.02$ & $8 \pm 0.04^{*}$ & $10 \pm 0.04^{*}$ & $\begin{array}{c}12 \pm \\
0.02^{*}\end{array}$ \\
\hline $\begin{array}{c}\text { Child grinds } \\
\text { teeth during } \\
\text { sleep }\end{array}$ & $13 \pm 0.01^{*}$ & $7 \pm 0.02^{*}$ & $5 \pm 0.07$ & $10 \pm 0.08$ \\
\hline \multicolumn{2}{|c|}{} & & & \\
\hline
\end{tabular}

Table 2: ${ }^{*} \mathrm{p}<0.05^{* *} \mathrm{p}<0.01$.

On average, sleep behaviour of the children with DS had earlier wake times and bedtimes, leading to significantly more hours of sleep during nights, largely due to significantly earlier bedtimes. There was mild statistically significant difference in the amount of sleep time compared to normal children.

\section{Night waking}

On average, night waking of the children with DS had difference when compared to normal children, leading to troubling in getting sleep during nights after the child wake up. There is no difference in other parameters.

\begin{tabular}{|c|c|c|c|c|}
\hline & $\begin{array}{c}\mathbf{3}-\mathbf{5} \text { yrs } \\
\text { (n= 15) }\end{array}$ & $\begin{array}{c}\mathbf{5} \text { - 8 yrs } \\
\text { (n= 8) }\end{array}$ & $\begin{array}{c}\mathbf{8} \text { - 10 yrs } \\
\text { (n= 11) }\end{array}$ & $\begin{array}{c}\text { > 10 yrs } \\
\text { (n = 15) }\end{array}$ \\
\hline $\begin{array}{c}\text { Child wakes up once } \\
\text { during the night. }\end{array}$ & $13 \pm 0.01$ & $7 \pm 0.04$ & $4 \pm 0.08$ & $7 \pm 0.06$ \\
\hline $\begin{array}{c}\text { Child having trouble to } \\
\text { get back to sleep }\end{array}$ & $12 \pm 0.08$ & $4 \pm 0.09$ & $10 \pm 0.07$ & $12 \pm 0.04$ \\
\hline $\begin{array}{c}\text { Child wakes up more } \\
\text { than once during the } \\
\text { night }\end{array}$ & $9 \pm 0.01$ & $2 \pm 0.07$ & $8 \pm 0.08$ & $6 \pm 0.04$ \\
\hline $\begin{array}{c}\text { Child talk during the } \\
\text { sleep }\end{array}$ & $7 \pm 0.08$ & $3 \pm 0.02$ & $6 \pm 0.03$ & $8 \pm 0.04$ \\
\hline
\end{tabular}

Table 3: ${ }^{*} \mathrm{p}<0.05$

Morning wake up

\begin{tabular}{|c|c|c|c|c|}
\hline & $\begin{array}{c}\mathbf{3}-\mathbf{5} \text { yrs } \\
\text { (n= 15) }\end{array}$ & $\begin{array}{c}\mathbf{5} \text { - 8 yrs } \\
\text { (n= 8) }\end{array}$ & $\begin{array}{c}\mathbf{8}-\mathbf{1 0} \text { yrs } \\
\text { (n= 11) }\end{array}$ & $\begin{array}{c}\text { > 10 yrs } \\
\text { (n= 15) }\end{array}$ \\
\hline $\begin{array}{c}\text { Child wakes up } \\
\text { by himself }\end{array}$ & $\begin{array}{c}15 \pm \\
0.07^{*}\end{array}$ & $7 \pm 0.09^{*}$ & $\begin{array}{c}11 \pm \\
0.04^{*}\end{array}$ & $\begin{array}{c}15 \pm \\
0.08^{*}\end{array}$ \\
\hline $\begin{array}{c}\text { Child wakes up } \\
\text { very early in the } \\
\text { morning }\end{array}$ & $9 \pm 0.04$ & $5 \pm 0.08$ & $7 \pm 0.09$ & $\begin{array}{c}11 \pm \\
0.02\end{array}$ \\
\hline $\begin{array}{c}\text { Child seems } \\
\text { tired during the } \\
\text { daytime }\end{array}$ & $0.08^{*}$ & $7 \pm 0.06$ & $10 \pm$ & $13 \pm$ \\
& & $0.07^{*}$ & $0.08^{*}$ \\
\hline $\begin{array}{c}\text { Child falls asleep } \\
\text { while involved in } \\
\text { activities }\end{array}$ & $7 \pm 0.03$ & $8 \pm 0.08$ & $11 \pm$ & $14 \pm$ \\
& & & $0.07^{*}$ & $0.09^{*}$ \\
\hline \multicolumn{2}{|c|}{} & & & \\
\hline
\end{tabular}

Table 4: ${ }^{*} \mathrm{p}<0.05$

On average, morning waking of the children with DS was identified that the child wakes up by own. It is also noted that the child is tired during day and some sleep during day time which is also significant.

Sleep anxiety

\begin{tabular}{|c|c|c|c|c|}
\hline & $\begin{array}{c}\mathbf{3}-\mathbf{5} \text { yrs } \\
(\mathbf{n = 1 5})\end{array}$ & $\begin{array}{c}\mathbf{5}-\mathbf{8} \text { yrs } \\
(\mathbf{n = 8 )}\end{array}$ & $\begin{array}{c}\mathbf{8}-\mathbf{1 0} \text { yrs } \\
(\mathbf{n = 1 1 )}\end{array}$ & $\begin{array}{c}>10 \text { yrs } \\
\text { (n= 15) }\end{array}$ \\
\hline $\begin{array}{c}\text { Needs parents in } \\
\text { room to sleep }\end{array}$ & $\begin{array}{c}13 \pm \\
0.09^{*}\end{array}$ & $8 \pm 0.07^{*}$ & $11 \pm 0.06^{*}$ & $\begin{array}{c}13 \pm \\
0.03^{*}\end{array}$ \\
\hline $\begin{array}{c}\text { Afraid to sleep in } \\
\text { dark }\end{array}$ & $7 \pm 0.02$ & $6 \pm 0.01$ & $8 \pm 0.08$ & $12 \pm 0.09$ \\
\hline $\begin{array}{c}\text { Afraid to sleep } \\
\text { alone }\end{array}$ & $12 \pm$ & $8 \pm 0.09$ & $11 \pm 0.07^{*}$ & $\begin{array}{c}11 \pm \\
0.08^{*}\end{array}$ \\
\hline Trouble in sleeping & $6 \pm 0.01$ & $9 \pm 0.03$ & $10 \pm 0.06^{*}$ & $9 \pm 0.08^{*}$ \\
\hline
\end{tabular}

Table 5: ${ }^{*} \mathrm{p}<0.05$ 
On average, sleep anxiety of the children with DS needed some assistance during sleep, leading to trouble without assistance, is significant. The child is not afraid of dark when compared to normal children.

\section{Sleep duration}

\begin{tabular}{|c|c|c|c|c|}
\hline & $\begin{array}{c}\mathbf{3}-\mathbf{5} \text { yrs } \\
(\mathbf{n}=\mathbf{1 5})\end{array}$ & $\begin{array}{c}\mathbf{5}-\mathbf{8} \text { yrs } \\
\text { (n= 8) }\end{array}$ & $\begin{array}{c}\mathbf{8}-\mathbf{1 0} \text { yrs } \\
\text { (n= 11) }\end{array}$ & $\begin{array}{c}>10 \text { yrs } \\
\text { (n = 15) }\end{array}$ \\
\hline Sleep too little & $11 \pm 0.07^{*}$ & $6 \pm 0.07^{*}$ & $10 \pm 0.04^{*}$ & $9 \pm 0.03^{*}$ \\
\hline $\begin{array}{c}\text { Sleep the right } \\
\text { amount }\end{array}$ & $7 \pm 0.02$ & $8 \pm 0.08$ & $9 \pm 0.09$ & $8 \pm 0.07$ \\
\hline $\begin{array}{c}\text { Sleep same } \\
\text { amount each day }\end{array}$ & $10 \pm 0.01^{*}$ & $6 \pm 0.02$ & $11 \pm 0.05^{*}$ & $11 \pm 0.04^{*}$ \\
\hline $\begin{array}{c}\text { Sleep along with } \\
\text { snoring }\end{array}$ & $8 \pm 0.04$ & $7 \pm 0.02$ & $11 \pm 0.07^{*}$ & $13 \pm 0.09^{*}$ \\
\hline
\end{tabular}

Table 6: ${ }^{*} \mathrm{p}<0.05$.

On average, sleep duration of the children with DS found to be more when compared to normal children, is significant. The child don't sleep the same amount every day which was a significant finding.

\section{Discussion and Conclusion}

The psychometric properties of a modified sleep screening questionnaire designed to survey sleep patterns and sleep disturbances in Down Syndrome children are described in this paper. While there was overlap in the distribution of scores, the validity of the modified questionnaire was not determined by the ability of the elements, subscales, and total score of the modified questionnaire to reliably separate Down syndrome children and non-sleep disordered children from those requesting an assessment due to a suspected sleep disorder [27].

The sleep period score was significantly higher in older (13 - 18 years) children with normal growth, suggesting shorter sleep time in this group and longer sleep time in the DS group; however, the daytime sleepiness score was significantly higher in children with DS in the same age range, possibly indicating more fragmented sleep due to sleep disorder. With the exception of communication, sleep disordered breathing was a major explanatory factor in all domains of life patterns in children with DS [28]. None of the sleep disruption factors were found to be a major predictor of communication abilities in children with Down syndrome. Communication problems in DS are common, complex, and linked to oral motor and hearing abilities [29]. More research is needed to better understand the etiology of communication disorders and any possible links to sleep.

The importance of sleep anxiety found in our research is consistent with the correlation of sleep disorders with other sleep problems such as night wakings, sleep duration, parasomnias, and even sleep anxiety and bedtime resistance, where breathing difficulties may be thought of as an instigator for these additional behavioral rather than physiological disruptions. Sleep disruptions were similar in children without DS; but, in children with DS, the symptoms are exacerbated by the underlying developmental delay [30].

According to these findings, the existence of Down syndrome, although a significant explanatory factor, may not be the only one that influences functional and achievement outcomes in children with DS. Sleep disruptions are related to decreased successful function in everyday activities, mood impairments, behaviour, and daily success in the general population of children, so this may be a key clinical problem for children with DS [31]. Clinical treatment for sleep disturbances can result in improved daily function and quality of life for children and their families.

Improvements in these domains can further promote the child's active involvement in developmentally appropriate accomplishment of day-to-day life behaviors, as adequate sleep is shown to improve cognitive performance and learning [32].

Sleep disruptions are significant explanatory factors affecting many functional outcomes in children with Down syndrome, according to the findings of this review.

A child's intellectual level, the availability and severity of educational interventions, family habits and climate, general health, and the prevalence of thyroid disease, are all factors that could affect the treatment outcomes. The report did not collect data on income or race because it was beyond the scope of the study to look at the impact of these potentially confounding factors. Other known and unknown variables can also have an effect on the success of everyday behaviours and activities.

The study's methodology was subjective, based on parental reports; however, the study was conducted using well-established 
and previously validated questionnaire methods. The treatment of sleep problems in children with DS can result in improved daily life habits and activities. Future objective studies are required to better understand the correlation between sleep and functional abilities.

\section{Bibliography}

1. Punjabi NM. "The epidemiology of adult obstructive sleep apnea". Proceedings of the American Thoracic Society - ATS Journals 5.2 (2008): 136-143.

2. Heinzer R., et al. "Prevalence of sleep-disordered breathing in the general population: the Hypnolaus study". The Lancet Respiratory Medicine 3.4 (2015): 310-318.

3. Antic NA., et al. "The effect of CPAP in normalizing daytime sleepiness, quality of life, and neurocognitive function in patients with moderate to severe OSA". Sleep 34.1 (2011): 111119.

4. Choi JH., et al. "Predictive models of objective oropharyngeal OSA surgery outcomes: success rate and AHI reduction ratio". PLoS One 12.9 (2017): e0185201.

5. Simpson L., et al. "High prevalence of undiagnosed obstructive sleep apnoea in the general population and methods for screening for representative controls". Sleep Breath 17.3 (2013): 967-973.

6. Gray EL., et al. "Obstructive Sleep Apnea without Obesity Is Common and Difficult to Treat: Evidence for a Distinct Pathophysiological Phenotype". Journal of Clinical Sleep Medicine 13.1 (2017): 81-88.

7. Spicuzza L., et al. "Obstructive sleep apnoea syndrome and its management". Therapeutic Advances in Chronic Disease 6.5 (2015): 273-285.

8. Antonopoulos C., et al. "Nasal continuous positive airway pressure (nCPAP) treatment for obstructive sleep apnea, road traffic accidents and driving simulator performance: a meta-analysis". Sleep Medicine Reviews 15 (2011): 301-310.

9. Horner RL., et al. "State-dependent and reflex drives to the upper airway: basic physiology with clinical implications". Journal of Applied Physiology 116.3 (2014): 325-336.

10. Kapur VK., et al. "Clinical Practice Guideline for Diagnostic Testing for Adult Obstructive Sleep Apnea: An American Academy of Sleep Medicine Clinical Practice Guideline". Journal of Clinical Sleep Medicine 13.3 (2017): 479-504.
11. Temirbekov D., et al. "The Ignored Parameter in the Diagnosis of Obstructive Sleep Apnea Syndrome: The Oxygen Desaturation Index". Turkish Archives Of Otorhinolaryngology 56.1 (2018): 1-6.

12. Eckert DJ. "Phenotypic approaches to obstructive sleep apnoea - new pathways for targeted therapy". Sleep Medicine Reviews 37 (2018): 45-59.

13. Eckert DJ., et al. "Defining phenotypic causes of obstructive sleep apnea. Identification of novel therapeutic targets". American Journal of Respiratory and Critical Care Medicine 188.8 (2013): 996-1004.

14. Dewan NA., et al. "Intermittent hypoxemia and OSA: implications for comorbidities". Chest 147.1 (2015): 266-274.

15. Sankari A., et al. "Characteristics and Consequences of Nonapneic Respiratory Events During Sleep”. Sleep 40.1 (2017).

16. Wellman A., et al. "A method for measuring and modeling the physiological traits causing obstructive sleep apnea". Journal of Applied Physiology 110.6 (2011 1985): 1627-1637.

17. Peppard PE., et al. "Prospective study of the association between sleep-disordered breathing and hypertension". The New England Journal of Medicine 342 (2000): 1378-1384.

18. Dempsey JA., et al. "Pathophysiology of sleep apnea". Physiological Reviews 90.1 (2010): 47-112.

19. Strohl KP., et al. "Mechanical properties of the upper airway". Comprehensive Physiology 2.3 (2012): 1853-1872.

20. Chi L., et al. "Identification of craniofacial risk factors for obstructive sleep apnoea using three-dimensional MRI". European Respiratory Journal 38.2 (2011): 348-358.

21. Ch'ng CL., et al. "Celiac disease and autoimmune thyroid disease”. Clinical Medicine and Research 5.3 (2007): 184-192.

22. MA Carno., et al. "Symptoms of sleep apnea and polysomnography as predictors of poor quality of life in overweight children and adolescents". Journal of Pediatric Psychology 33.3 (2008): 269-278.

23. Maris M., et al. "Prevalence of Obstructive Sleep Apnea in Children with Down Syndrome”. Sleep 39.3 (2016): 699-704.

24. Simpson R., et al. "Obstructive sleep apnea in patients with Down syndrome: current perspectives". Nature and Science of Sleep 10 (2018): 287-293. 
25. Eckert DJ., et al. "Central sleep apnea: Pathophysiology and treatment". Chest 131.2 (2007): 595-607.

26. Bonuck KA., et al. "Modified Children's sleep habits questionnaire for behavioral sleep problems: A validation study". Sleep Health 3.3 (2017): 136-141.

27. Grantham-Hill S., et al. "Psychometric Properties and Predictive Value of a Screening Questionnaire for Obstructive Sleep Apnea in Young Children With Down Syndrome". Front Psychiatry 11 (2020): 285.

28. Esbensen AJ and Hoffman EK. "Reliability of parent report measures of sleep in children with Down syndrome". Journal of Intellectual Disability Research 61.3 (2017): 210-220.

29. Martin GE., et al. "Language Characteristics of Individuals with Down Syndrome”. Public Language Discord 29.2 (2009): 112132.

30. Abbeduto L., et al. "Receptive language skills of adolescents and young adults with Down or fragile X syndrome". American Journal on Mental Retardation 108 (2003): 149-160.

31. Ogundele MO. "Behavioural and emotional disorders in childhood: A brief overview for paediatricians". World Journal of Clinical Pediatrics 7.1 (2018): 9-26.

32. Moturi S and Avis K. "Assessment and treatment of common pediatric sleep disorders". Psychiatry 7.6 (2010): 24-37.

Volume 4 Issue 10 October 2021

(C) All rights are reserved by Priya Chandrasekhar., et al.

Citation: Priya Chandrasekhar., et al. "A Systemic Investigation to Compare the Relationship of Sleep Disturbances and its Outcomes in Normal and DS Children". Acta Scientific Paediatrics 4.10 (2021): 63-70. 